mSASSS value was 3.8 (IQR 1.0-22.1) in AS und 0.0 (IQR 0.0-1.4) in nr-axSpA patients. The mean Berlin AS Spine Score for patients with axSpA was 5.3 (SD 7.1). Patients received a treatment with NSAIDs (62.7\%), DMARDs (20.9\%) and/ or biologics (49.4\%). A significant correlation of the ASAS HI was found for BASMI $(r=0.5)$, BASDAI $(r=0.7)$, ASDAS $(r=0.5)$, BASFI $(r=0.8)$, BMI $(0.3)$ and Berlin Score (0.3). ASAS HI did not correlate with radiographic damage (mSASSS $r=0.2$, presence of bamboo spine $r=0.2)$ and CRP $(r=0.07)$. Stratifying patients by symptom duration (cut-off 3 years) did not affect these results. Logistic regression showed influence of obesity but not of inflammation or structural damage on global functioning (table 1).

Abstract AB0893 - Table 1

\begin{tabular}{lcccc}
\hline & \multicolumn{2}{c}{ Univariable } & \multicolumn{2}{c}{ Multivariable } \\
\hline & OR $(\mathrm{Cl})$ & $\mathrm{p}$ & $\mathrm{OR}(\mathrm{Cl})$ & $\mathrm{p}$ \\
\hline Age & $1.04(1.02-1,06)$ & $\mathbf{0 . 0 0 1}$ & - & $\mathrm{NS}$ \\
Male sex & $0.47(0.24-0.93)$ & 0.003 & $0.09(0.01-0.71)$ & $\mathbf{0 . 0 2 2}$ \\
BMI & $1.10(1.03-1,18)$ & 0.006 & $1.24(1.05-1.48)$ & $\mathbf{0 . 0 1 3}$ \\
BASDAl, 0-10 & $1.35(1.17-1.57)$ & $<0.001$ & - & $\mathrm{NS}$ \\
ASDAS & $2.51(1.76-3.57)$ & $<0.001$ & - & $\mathrm{NS}$ \\
BASFI, 0-10 & $2.03(1.66-2.48)$ & $<0.001$ & $1.85(1.19-2.87)$ & $\mathbf{0 . 0 0 6}$ \\
BASMI, 0-10 & $2.0(1.56-2.54)$ & $<0.001$ & - & $\mathrm{NS}$ \\
mSASSS, 0-72 & $1.02(1.00-1.05)$ & 0.089 & - & $\mathrm{NS}$ \\
Berlin Score, 0-72 & $0.98(0.91-1.04)$ & 0.490 & - & $\mathrm{NS}$
\end{tabular}

Conclusions: The influence of obesity on functioning is remarkable in patients with SpA. In contrast, the influence of structural damage and spinal inflammation on functioning was limited in this study, probably due to the relatively low mSASSS and MRI scores. Further studies with inclusion of more severely affected patients are needed to study the association of functioning, spinal mobility, obesity and radiographic damage over a broader range of affected patients. Disclosure of Interest: None declared

DOI: 10.1136/annrheumdis-2018-eular.2480

\section{AB0894 A COMPARISON OF CLINICAL FEATURES IN PATIENTS WITH SPONDYLOARTHRITIS AND UNILATERAL OR BILATERAL HIP ARTHRITIS}

W. Hamdi ${ }^{1}$, S. Zrida ${ }^{1}$, H. Riahi' ${ }^{2}$, K. Maatallah ${ }^{1}$, D. Kaffel ${ }^{1}$, M. Chelli Bouaziz ${ }^{2}$, M. F. Ladeb ${ }^{2}$, M.M. Kchir ${ }^{1}{ }^{1}$ Rheumatology, ${ }^{2}$ Radiology, Institute Mohamed Kassab, Ksar Said, Manouba, Tunisia

Background: Axial spondyloarthritis (AS) is a frequent chronic and progressive disease that affects mainly young adults and is characterised by inflammation of the axial skeleton, but peripheral joints such as hips may also be involved. The incidence of hip involvement in AS is around $30 \% .{ }^{1}$ Nevertheless, data concerning clinical features in patients with spondyloarthritis comparing unilateral and bilateral hip arthritis are lacking

Objectives: To compare clinical, functional and radiologic outcomes in patients with AS with unilateral or bilateral hip arthritis.

Methods: Cross-sectional study on 100 patients with AS according to the ASAS criteria of ${ }^{2009}$ who had unilateral and bilateral hip joint lesions defined by hip pain, limited joint motion and radiographic hip abnormalities. Demographic and clinical outcomes were performed including HLA B27 status. Spinal mobility outcomes were assessed by Schöber index and Bath Ankylosing Spondylitis Metrology Index $(B A S M)$. Radiographic measurements were performed and included Bath Ankylosing Spondylitis Radiology Index (BASRI) and modified Stoke Ankylosing Spondylitis Spinal Score (mSASSS).

Results: Bilateral hip joint lesion was reported in $76 \%$ of patients which 14 were women and mean age was 37.14 years. Bilateral hip involvement was associated with less height $(\mathrm{p}=0.002)$, more long disease duration $(\mathrm{p}=0.015)$, more several clinical spinal involvements with more spinal stiffness $(p=0.000)$ and less spinal mobility $(p=0.004)$. Extra-articular manifestations were comparable in patients with unilateral and bilateral hip arthritis $(p=0.55)$, however HLA B27 antigen was significantly more common $(p=0.003)$ in patients with bilateral hip arthritis. BASRI hip $(p=0.042)$ and mSASSS $(p=0.009)$ scores were used to asses structural damage on plain radiographs and were significantly more important in bilateral involvement. Nevertheless, protrusive form was more frequent in patient with unilateral hip involvement $(p=0.05)$

Conclusions: Bilateral hip arthritis seems to be more frequent and more severe than unilateral involvement in patients with AS.

REFERENCE:

[1] A. Calin, J. Elswood. The relationship between pelvic, spinal and hip involvement in ankylosing spondylitis: one disease process or several? Br J Rheumatol, 27 (1988), pp. 393-395
Disclosure of Interest: None declared

DOI: 10.1136/annrheumdis-2018-eular.6834

\section{AB0895 1 ARE LATERAL SPINE BONE MINERAL DENSITY MEASUREMENTS USEFUL IN AXIAL SPONDYLOARTHRITIS?}

W. Hamdi ${ }^{1}$, D. Ben Nessib ${ }^{1}$, H. Riahi' ${ }^{2}$, A. Kasraoui ${ }^{1}$, K. Maatallah ${ }^{1}$, M.D. Kaffel ${ }^{1}$, M. Bouaziz ${ }^{2}$, M.F. Ladeb ${ }^{2}$, M.M. Kchir ${ }^{1} .{ }^{1}$ Rheumatology; ${ }^{2}$ Radiology, Kassab Hospital, Tunis, Tunisia

Background: Bone loss leading to osteoporosis (OP) is a well-known feature of axial spondyloarthritis (AS) although this disease is characterised by calcification in extra osseous tissues and new bone formation. In fact, dual-energy X-ray absorptiometry (DEXA) is the most common imaging method used to measure the bone mineral density (BMD). However, many studies have shown an inferiority of the postero-anterior (PA) spine measurements in reflecting the bone loss compared to lateral spine measurements because of the bridging syndesmophytes which may overestimate the BMD.

Objectives: Our aim is to evaluate the Lateral spine BMD (L-BMD) in AS and to assess its association with the disease features.

Methods: Seventy-five patients who met the Modified New York Classification criteria for AS were enrolled in this cross-sectional study. BMD was measured using DEXA at PA lumbar, lateral lumbar and hip regions.

Results: Sixty-two men and 13 women were enrolled with an average age of 36.8 \pm 11.8 years. Bone loss (osteopenia or OP) was noted in $65 \%$ of the patients $(n=46)$ in PA lumbar and in $63 \%$ in lateral lumber $(n=45)$. In L-BMD, BMD was correlated with early menopause and vitamin $D$ level $(p=0.01$ and $p=0.04$ respectively). T-score in lateral spine was correlated with coffee consumption $(p=0.02)$ physical inactivity $(p=0.037)$, sexual hormones disorders $(p=0.02)$, hip arthritis $(p=0.017)$, BASMI $(p=0.001), B A S F I(p=0.03)$ and ASDAS $(p=0.03)$ scores, ESR $(p=0.003)$ and CRP $(p=0.03)$ levels, and hip $(p=0.004)$, spine $(p=0.007)$ and total $(p=0.001)$ BASRI.

Conclusions: L-BMD seems to be a reliable measurement in AS, and may avoid the overestimation of the BMD values and allows consequently to detect spinal osteoporosis and prevent fractures in AS.

\section{REFERENCES}

[1] El Maghraou A, Borderie D, Cherruau B, Edouard R, Roux C, Dougados M (1999) Osteoporosis, body composition, and bone turnover in ankylosing spondylitis. J Rheumatol 26:2205-2209

[2] Mitra D, Elvins DM, Speden DJ, Collins AJ (2000) The prevalence of vertebral fractures in mild ankylosing spondylitis and their relationship to bone mineral density. Rheumatology 39:85-89

Disclosure of Interest: None declared

DOI: 10.1136/annrheumdis-2018-eular.5397

\section{AB0896 1 ASSOCIATION OF IGA ANTIBODIES AGAINST CD74 WITH PRODUCTION OF IL17A BUT NOT OF TNFALPHA IN PATIENTS WITH ACTIVE AXIAL SPONDYLOARTHRITIS}

X. Baraliakos ${ }^{1}$, K. Kniesch ${ }^{2}$, N. Baerlecken ${ }^{2}$, J. Braun ${ }^{1}$, T. Witte ${ }^{2} .{ }^{1}$ Rheumazentrum Ruhrgebiet, Herne; ${ }^{2}$ Medizinische Hochschule Hannover, Hannover, Germany

Background: Axial spondyloarthritis (axSpA) is strongly associated with HLAB27. Recently, IgA antibodies (Abs) against CD74 (IgA-anti-CD74) and T-cells carrying CD-74-specific T-cell receptors were also found to be associated with axSpA, especially in patients with ankylosing spondylitis, the radiographic form of axSpA. Tumour necrosis alpha (TNF $\alpha$ ) inhibitors and IL-17 antagonists are efficacious in patients with active axSpA.

Objectives: To investigate whether IgA-anti-CD74 Abs are associated with proinflammatory cytokines in the sera of patients with HLA-B27-positive and -negative patients with active axSpA.

Methods: Blood samples of 62 HLA-B27-positive and 58 HLA-B27-negative patients with axSpA (44\% AS) prior to starting a biologic therapy were collected. A cytometric bead-array (CBA Flex Set) was used to measure serum levels of interleukin (IL)-17A, IL-6, IL-1 $\alpha$, TNF $\alpha$, and interferon (INF)- $\gamma$. IgA-anti-CD74 Abs were measured by ELISA, using the predefined cut-off of $15 \mathrm{U} / \mathrm{ml}$. Their mean concentrations were compared between groups using $\mathrm{T}$-tests. The patients who were positive or negative for IgA-anti-CD74 Abs were compared using chi-square test.

Results: IgA-anti-CD74 Abs were detected in 54/120 axSpA patients (45\%). There were no differences in the baseline demographics and clinical assessments in patients with or without IgA-anti-CD74 Abs. The presence of IgA-anti-CD74 Abs 
was associated with higher serum concentrations of IL-17A ( $p=0.01$ ), irrespective of the presence of HLA-B27, CRP and IL-6 (both $p<0.05)$ but not TNFa $(p=0.2)$. Conclusions: In a cross-sectional study, the presence of IgA Abs against CD74 was associated with serum levels of pro-inflammatory biomarkers such as CRP (and IL-6) and IL-17 but not TNFa irrespective of HLA-B27 status. Longitudinal prospective studies are needed to show that the measurement of IgA anti-CD74 Abs and/or serum cytokines can help to guide treatment decisions.

Acknowledgements: We thank Novartis Pharma AG for the support of our study.

Disclosure of Interest: X. Baraliakos: None declared, K. Kniesch: None declared, N. Baerlecken: None declared, J. Braun: None declared, T. Witte Grant/ research support from: Novartis

DOI: 10.1136/annrheumdis-2018-eular.5570

\section{AB0897 THE RELATIONSHIP BETWEEN DISEASE-SPECIFIC INDICES AND BALANCE IN PATIENTS WITH ANKYLOSING SPONDYLITIS}

Y. Acar ${ }^{1}$, N. İlçin ${ }^{1}$, B. Gürpınar ${ }^{1}$, G. Can ${ }^{2}$, F. Önen ${ }^{2} .{ }^{1}$ Physical Theraphy and Rehabilitation; ${ }^{2}$ Rheumatology, Dokuz Eylül University, izmir, Turkey

Background: Axial and periferal joint stifness, impaired joint mobility and postural deformities may affect balance in AS. However factors affecting balance in AS patients are still unclear. There is limited literature investigating balance-related factors in patients with AS and the results are contradictory.

Objectives: The aim of the study was to investigate relationship between disease-specific indices and balance in patients with AS.

Methods: 72 patients(46 male, 26 female) with AS were included in the study. The demographic and anthropometric features(age, weight, height, body mass Index(BMI)) of patients were recorded. Disease-specific indices used in the study were Bath Ankylosing Spondylitis Disease Activity Index (BASDAI), Bath Ankylosing Spondylitis Functional Index (BASFI) and Bath Ankylosing Spondylitis Mobility Index (BASMI). BASDAI for disease activity, BASFI for functional capacity, BASMI for spinal mobility were used. Static and dynamic balance was evaluated with Biodex Balance System SD. Limits of stability and bilateral stance (stable and unstable platform), single leg stance (stable platform) postural stability test results were recorded. Overall stability $(\mathrm{OA})$ indices were used. A high score in the OA index indicates poor balance. Spearman correlation test used for statistical analysing. Correlation analyses were performed between BASDAI, BASFI, BASMI scores and Biodex test results

Results: The mean age of patients was $39,95 \pm 8,84$ years and mean BMI was $26,55 \pm 3,82 \mathrm{~kg} / \mathrm{m}^{2}$. BASDAI, BASFI and BASMI scores of patients are shown in table 1.

Abstract AB0897 - Table 1. BASDAI, BASMI and BASFI scores

\begin{tabular}{lc}
\hline & $\begin{array}{c}\text { AS patients }(\mathrm{n}=72) \\
\text { Median }(\text { IQR 25- } \\
\end{array}$ \\
\hline BASDAI & $75)$ \\
BASFI & $2,10(1,02-3,78)$ \\
BASMI & $1,10(0,30-2,74)$ \\
\hline
\end{tabular}

Only positive weak correlation was found between BASFI score and right leg stance overall postural stability index $(r=0,25, p=0,034)$. No other correlation was detected between BASDAI, BASFI, BASMI scores and Biodex balance test results.

Conclusions: The results of our study indicated that there is no relationship between BASDAI, BASFI, BASMI scores and balance except BASFI score and right leg stance postural stability. Our results contradict some previous studies while supporting some studies. This may be due to in our study BASDAI, BASFI and BASMI scores are lower than previous studies or the usage of different methods from previous studies for evaluating balance and postural stability in AS. Further studies are required to establish the actual status of relationship between balance and clinic measurements in AS patients.

\section{REFERENCE:}

[1] Pompeu, J.E., Static and dynamic balance in subjects with ankylosing spondylitis: literature review. Revista brasileira de reumatologia, 2012. 52 (3): p. 413-416.

Disclosure of Interest: None declared DOI: 10.1136/annrheumdis-2018-eular.5126

\section{AB0898 \\ COURSE OF ANKYLOSING SPONDYLITIS IN PREGNANCY}

Z. Gandaloeva, O. Kritchevskaya, T. Dubinina, S. Erdes. Laboratory of spondyloarthritis, V. A. Nasonova Research Institute of Rheumatology, Moscow, Russian Federation

Objectives: To study the effect of pregnancy on ankylosing spondylitis (AS) course.

Methods: 86 AS patients having pregnancy in the course of the disease were included into questionnaire survey. Patients' mean age was 34 [30:37] years mean disease duration was 120 [72:180] month. The questionnaire items were designed to elucidate modifications in AS course during the last pregnancy with live birth outcome. The study is based on patient's self-reported health (SRH) status (improvement, worsening, no change).

Results: All responders reported delivery of full-term babies at mean 39 weeks [38:40] of gestation, vaginal delivery was documented by $46(53,5 \%)$ responders, Caesarean section - by 40 (46,5\%). AS worsening or improvement during all three trimesters is shown in the table 1.

Abstract AB0898 - Table 1

\begin{tabular}{lcc}
\hline Trimester & Improvement $\mathrm{n}=42 /$ & Worsening $\mathrm{n}=58$ / \\
& $48,8 \%$ & $67,4 \%$ \\
\hline I & $30 / 34,8 \%$ & $15 / 17,4 \%$ \\
II & $21 / 24,4 \%$ & $26 / 30,2 \%$ \\
III & $18 / 20,9 \%$ & $36 / 41,8 \%$ \\
\hline
\end{tabular}

Comparison of improvement rates in I and III trimesters, $\mathrm{p}=0,05$

Worsening of underlying disease (as compared to the condition 3 months prior to pregnancy) during whole pregnancy was reported by $3(3,5 \%)$ women, absence of noticeable changes was reported by $13(15,1 \%)$ patients, and AS improvement - by $9(10,4 \%)$ participants.

$61(71 \%)$ of responders reported fluctuating AS activity during pregnancy. AS worsening was associated with exacerbation of back pain in $44(51 \%)$, emergence and/or recurrence of arthritis - in $15(17,4 \%)$, or uveitis - in $9(10,4 \%)$, and other symptoms - in $11(12,8 \%)$ patients.

Conclusions: Therefore, the majority of participants reported the diverse fluctuations in AS course during pregnancy, although $50 \%$ of responders reported the improvement in the course of the disease at least during one trimester (more often in the first). Nevertheless, almost $70 \%$ of responders reported AS worsening with exacerbations rates increasing in parallel with increasing gestation age. $50 \%$ of participants noticed worsening back pain, although special attention should be given to correct evaluation of AS activity in these patients keeping in mind the increased physiological load on the backbone during the second half of pregnancy.

Disclosure of Interest: None declared

DOI: 10.1136/annrheumdis-2018-eular.1968

\section{AB0899 ANKYLOSING SPONDYLITIS AND PREGNANCY: DATA FROM THE QUESTIONNAIRE SURVEY-BASED PILOT STUDY}

Z. Gandaloeva, O. Kritchevskaya, T. Dubinina, N. Kosheleva, S. Erdes. laboratory of spondyloarthritis, V. A. Nasonova Research Institute of Rheumatology, Moscow, Russia., Moscow, Russian Federation

Objectives: To study parity and pregnancy outcomes, as well as causes for not getting pregnant in women with ankylosing spondylitis (AS).

Methods: 326 AS female patients were covered by questionnaire survey during the period from November 2016 until October 2017. Mean age of the participants was 32 [28:36] years, mean AS duration - 102 [48:168] months. The questionnaire items covered such issues as prior pregnancies, maternal and neonatal outcomes and potential reasons for not getting pregnant.

Results: 194 (59\%) (mean age $34,1 \pm 5,4$ y) females out of 326 surveyed had from 1 to 8 pregnancies, totally 396 . Pregnancy outcomes are presented in the table 1 . 